\title{
Proposed Method for Two Axis Tracking of PV Modules Using Advanced Microcontroller
}

Emad A. Sweelem, Mohamed I. Abu El-Sebah, Fathy A. Syam, Abouelmaaty M.Aly, Hanaa M.Farghally

Electronics Research Institute,

National Research Center Building, Dokki, Giza, 12622

Egypt

Received: June 3, 2020. Revised: September 14, 2020. Accepted: September 28, 2020. Published: September 30, 2020.

\begin{abstract}
In this study, a stand-alone photovoltaic power system was designed and implemented to operate as an application of a digital control system. Sun-tracker is implemented for improved efficiency of the system by keeping the solar module perpendicular to the sun's incoming rays. An experimental system was implemented to demonstrate the effectiveness of the proposed system. Experimental results are given to verify the system's efficiency. A proposed method is employed to seek the maximum power point using two lighting sensors the data obtained from a two sensor is compared by microcontroller. Microcontroller is making PV module track the maximum sun light which leads to obtain a maximum power. The system is implemented using microcontroller and stepper motor and experimental work used to prove feasibility of the proposed method.

Keywords - Digital Control, Microcontroller, PV, Solar cell tracking.
\end{abstract}

\section{INTRODUCTION}

S. Shanmugam. et al. had. Given. the tracking. of the. Sun. for solar paraboloidal. dish concentrators in [1]. Rong. Jong. Wai et al. had. Given. Grid Connected photovoltaic (PV) generation. System. with an adaptive step-perturbation (ASP) method and an active sun tracking scheme [2]. Cemil. Sungur. Had. Given. the electromechanical. Control. System. of a PV tracking the sun through the axis it moved along according to its azimuth angle. [3]. The elevation. Angle. of the sun. be in the same place almost invariant in a month and varies. little (latitude $\pm 10^{\circ}$ ) in a year. So, a single axis position. Control scheme may be enough for the collection. of solar. Energy. in some applications. [4],[5]. So, the average of solar energy is not always maximized. Solar cell tracking system is essential for many applications such as thermal energy storage-systems and solar energy-based power-generation systems in order to get benefit to the system performance [6]. The variation in sun's position is monitored, and the system. Always. Keeps. That. the plane of the panel. is normal. to the direction. of the sun.,[6]. A little design. Methodologies. of PV tracking system have been introduced in recent days [7],[8]. The dual axis solar tracker uses an elevation actuator and an azimuth actuator to alter the azimuth of an attached solar panel. Microcontroller. control the actuator. controller circuit. that control the actuators. The Maximum. Power. point (MPP) tracking and output voltage. regulation (OVR) represent. the two control. Modes. of a MIC [9]. Both control modes are influenced. by the existence. of multiple. local maxima. and one global MPP on the power-voltage characteristics of the PV module [10],[11]. The existence of several local maxima is attributed to the mismatch. between the submodules. due to fabrication. tolerances, dust accumulation, or partial shading [12], [13], [14]. In this context, the efficacy. of both controls. 
modes rely. on various. factors. For the global MPP tracking. Mode., on the one hand, the utilized. number of sensors, speed. and accuracy. of tracking, ease. of implementation, and cost are used. for quality assessment. [15], [16]. On the other hand, tight dc bus voltage. control and balanced. power sharing between. sources, also low converter power. Losses. and the corresponding. Reduced. Heat. accumulation are the indicators of the quality of the OVR mode [17].

In this paper, the MPP system is designed and successfully implemented a digital controller system that is specifically used in photovoltaic. This system makes the solar panel tracking the light by using two photo sensors.

\section{MOTION OF THE SUN THROUGHOUT THE YEAR}

\section{A. Importance of Sun position}

Fig.1 shows the diagrammatic view where it shows the suns motion in summer, winter \& in spring. In a year sun takes different path in the sky. latitude only says the exact path of sun.

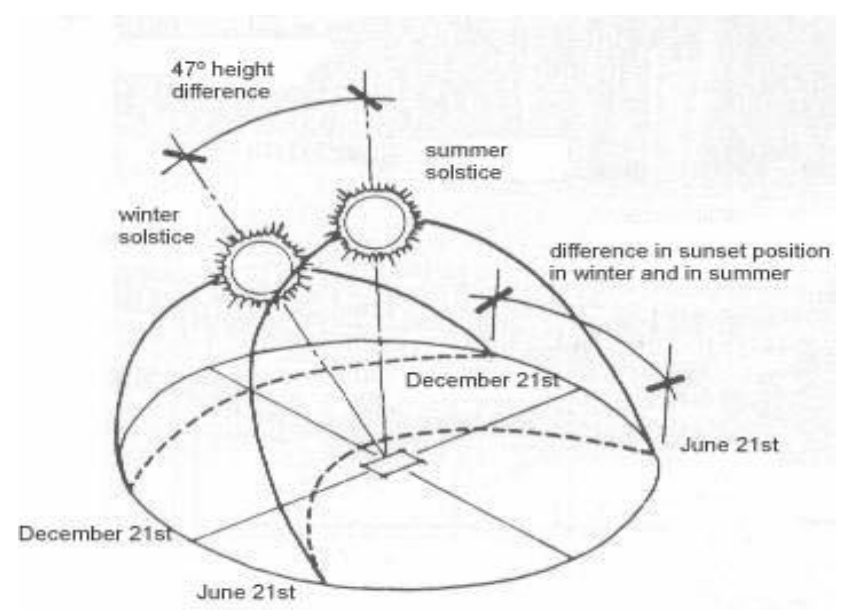

Fig. 1: Diagrammatic view of motion of the sun throughout the year.

\section{B. Dual-axis solar tracker}

It (Fig. 2) shows the block. diagram of dual axis solar. tracker. Normally solar panel generate. solar power which is used for charging 12-volt battery. PIC microcontroller only gets power from the voltage regulator which is derived by battery. LCD. is attached with microcontroller and for exchanging. information with a user a $4 \times 4$ matrix keypad is used.

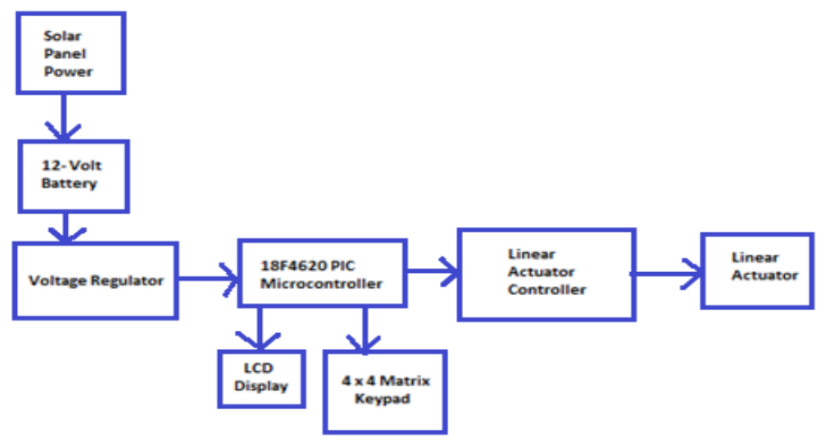

Fig. 2: Block diagram circuit for dual-axis solar tracker.

\section{MPP TRACKING SYSTEM DESIGN}

The dual axis tracking technique is designed to track the sun in both azimuth and altitude angles to enable the PV panel perpendicular to the illumination of the sun:

The PV panel used in this system amorphous silicon solar cell, the maximum output power is $60 \mathrm{~W}$, open circuit voltage is $22 \mathrm{~V}$, short circuit current is $3.4 \mathrm{~A}$ and its dimensions $315^{*} 925 \mathrm{~mm}$ and its weight $7.1 \mathrm{Kg}$ (Fig. 3)

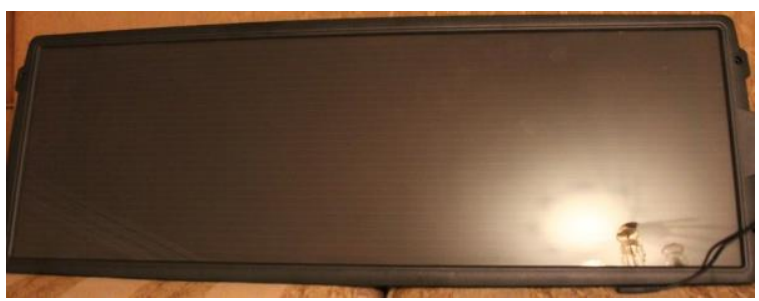

Fig. 3: Solar cell Module.

The mechanical mechanism as shown in Fig. 3 includes a stepper motor and DC motor. The system consists of PV panel, frame, stepper motor, DC motor, sensor circuit and driver circuits.

\section{A. Stepper Motor}

A direct current (DC) motor runs by itself when voltage is supplied to it. In a DC motor, a split-ring commutator switches the direction of the current through the magnetic field coils each half rotation to maintain the shaft's direction of motion. A stepper motor can be viewed as an electric motor without a commutator. All windings in the stepper motor are part of the stator. The rotor is a permanent magnet or, in the case of 
variable reluctance motors, a toothed block of some magnetically soft material. The motor controller handles all of the commutation externally. Typically, the motor and controller are designed so that the motor can be held in any fixed position as well as rotated one way or the other. With the appropriate controller, a stepper motor can start and stop "on a dime" at controlled orientations. The repeatability of positioning with a stepper motor depends on the geometry of the motor rotor. Some applications have the flexibility of using either stepper motors or servomotors. Although both types of motors offer similar opportunities for precise positioning, they differ in several ways. Servomotors require analog feedback control systems. Typically, this involves a potentiometer to provide feedback about the rotor position and circuitry to drive a current through the motor. The current is inversely proportional to the difference between the desired position and the current position. Stepper motors can be used in simple open-loop control systems. They are generally adequate for systems that operate at low accelerations with static loads.

\section{a. Stepper Motor Advantages}

1. The rotation angle of the motor is proportional to the input pulse.

2. The motor has full torque at standstill (if the windings are energized)

3. Precise positioning and repeatability of movement since good stepper motors have an accuracy of $3-5 \%$ of a step and this error is non-cumulative from one step to the next.

4. Excellent response to starting/ stopping/reversing.

5. Very reliable since there are no contact brushes in the motor. Therefore, the life of the motor is simply dependent on the life of the bearing.

6. The motors response to digital input pulses provides openloop control, making the motor simpler and less costly to control.

7. It is possible to achieve very low speed synchronous rotation with a load that is directly coupled to the shaft.

8. A wide range of rotational speeds can be realized as the speed is proportional to the frequency of the input pulses.

\section{EXPERIMENTAL WORK}

A proposed method is employed to seek the maximum power point using two lighting sensors the data obtained from a two sensor is compared by microcontroller. Microcontroller is making $\mathrm{PV}$ module track the maximum sun light which leads to obtain a maximum power. The system is implemented using microcontroller and stepper motor and experimental work used to prove feasibility of the proposed method.

\section{A. Interfacing Circuit.}

Fig. 4 shows the power supply implemented to feed each element in the whole circuit which ensure the supply to the circuit and the stepper motor. Interfacing circuit has been implemented to subject the PV module to the light ensuring the maximum power generated. The two light sensors which used to detect the light direction are connected as shown in Fig. 5. Stepper motor interfacing circuit is shown in Fig.6 which uses ULN 2003 as a driver to the stepper motor. The stepper motor control the movement of the PV system towards the light.

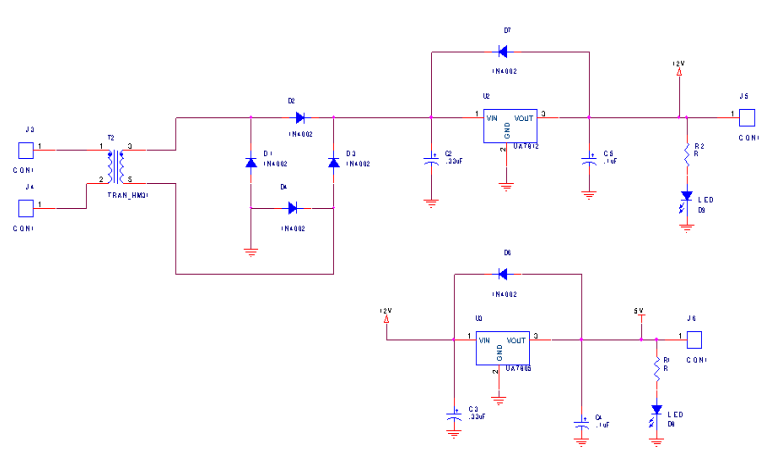

Fig. 4: The power supply schematic diagram 


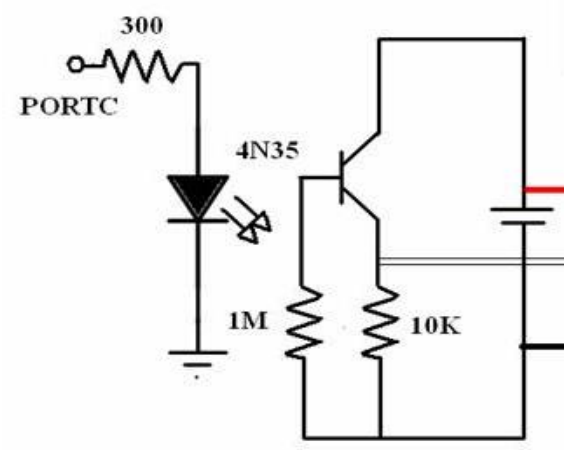

Fig. 5: The lighting sensor schematic diagram.
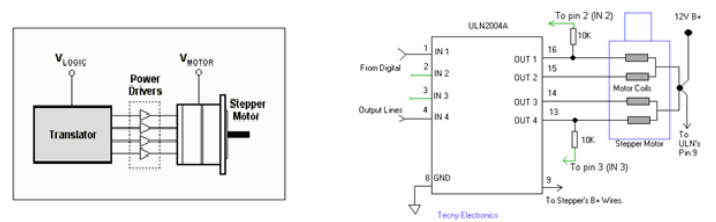

Fig. 6: Schematic diagram of the stepper motor drive circuit

\section{B. Software Program}

Flowchart of the software program is illustrated in the Fig. 7, which shows also the detailed flowchart. This flowchart is converted to assembly.
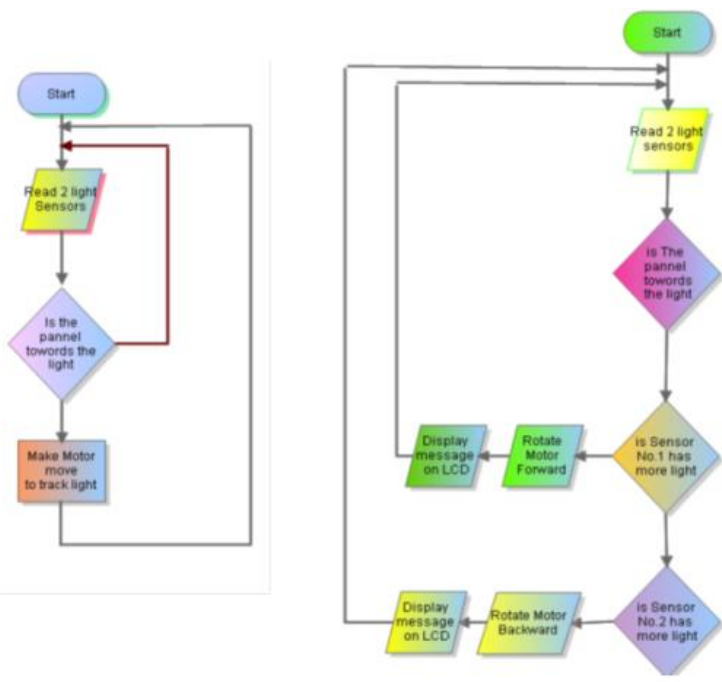

Fig. 7: The Control program flowchart

\section{System Implementation}

Figures 9,10 show the implemented system hardware. Fig. 8 shows the microcontroller Board used to control the tracker system, while the whole system is illustrated in Fig.9

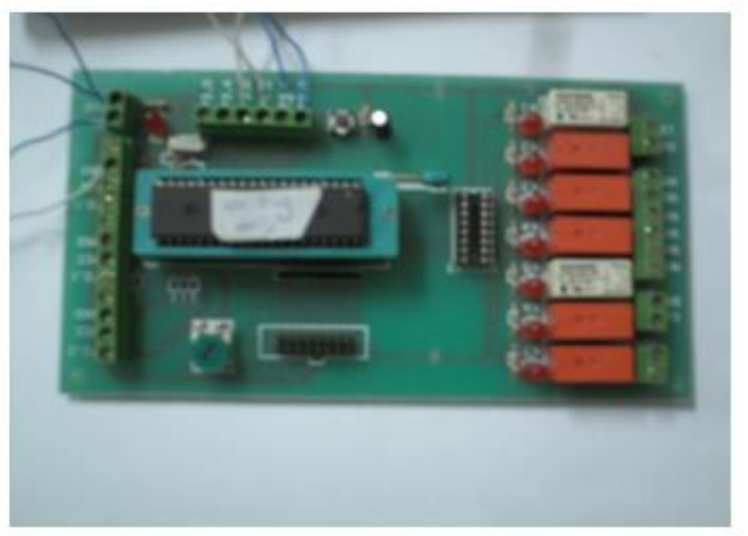

Fig. 8: the microcontroller Board.

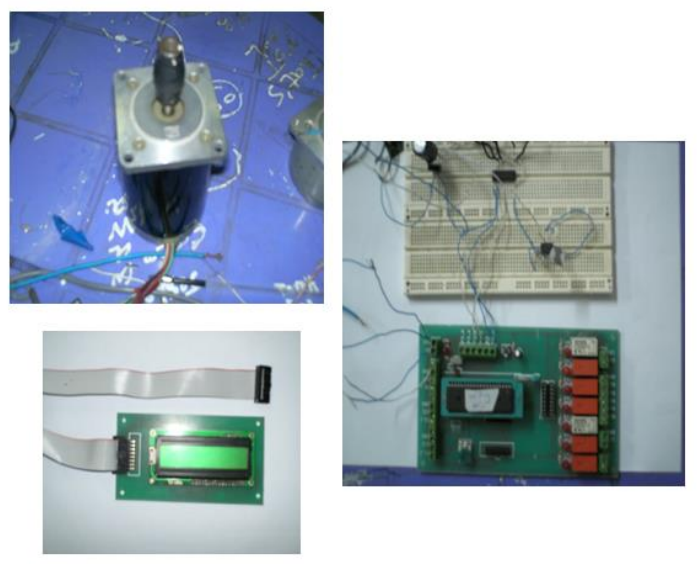

Fig. 9: the tracking control system.

\section{RESULTS}

The power resulting against time characteristic $(\mathrm{C} / \mathrm{C})$ is shown in Fig.10, indicate that there is an overall increase of output energy about $25 \%$ for the two-axis MPP tracking system compared to the fixed PV system as shown in Fig.11. The tracking mechanism can track the sun according to the direction of beam propagation of solar radiation and it has a provision. in the software for adjustment of the system in case of seasonal variation if necessary. The power. Consumption. by the system is very low because of low energy consumption devices are used like as COMS digital IC's and other low 
power consuming solid-state electronic components. Also, consumes. a small amount of energy. as it rotates only for a fraction of every interval of time.

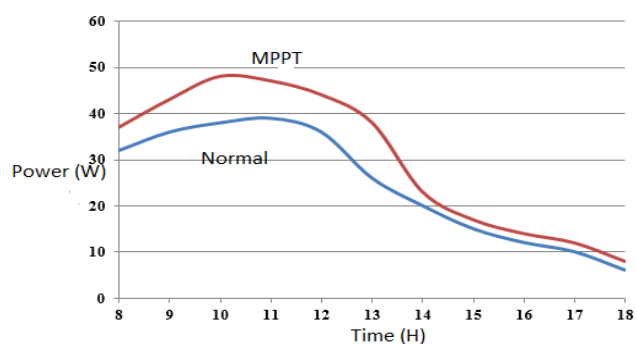

Fig. 10: Power-Time variation of Normal and MPPT.

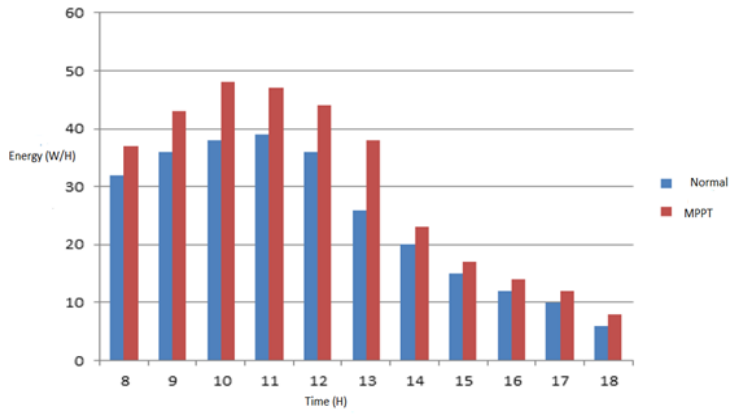

Fig. 11: Energy production comparing for normal and MPPT system.

\section{CONCLUSION}

In this paper, tracker for solar PV module system has been Designed and implemented with microcontroller using two light sensors and stepper motor controlling the module polarization. The system is controlled by $89 \mathrm{c} 52$ microcontroller to produce maximum available power that the PV array can generate under all operating conditions. The software and hardware have been tested and verified the required aim of design.

The proposed method offers advantages of simplified hardware configuration, low cost and fast convergence to reach the Maximum power.

\section{References}

[1] K. St., E. Abb., and D. N. Huu., "DC microgrid for wind and solar power integration," IEEE J. Emerg. Sel. Topics Power Electron., vol. 2, no. 1, pp. 115-126, Mar. 2014.
[2] G. AlLee and W. Tschudi, "Edison redux: $380 \mathrm{Vdc}$ brings reliability and efficiency to sustainable data centers," IEEE Power Energy Mag., vol. 10, no. 6, pp. 50-59, Nov.-Dec. 2012.

[3] E. Romero-Cadaval, G. Spagnuolo, L. G. Franquelo, C.Andr'es Ramos-Paja, T. Suntio, andW.-Michael Xiao, "Gridconnected photovoltaic generation plants: Components and operation," IEEE Ind. Electron. Mag., vol. 7, no. 3, pp. 6-20, Sep. 2013.

[4] L. Eggenschwiler,M. Adly, P. Favre-Perrod, and K. Strunz, "Closed-loop impedance calculation of grid-tied three-phase inverters/rectifiers in bus signaling strategy-controlled DC microgrids," in Proc. IEEE 2nd Int. Conf. DC Microgrids, Jun. 2017, pp. 309-315.

[5] R. C. N. Pilawa-Podgurski and D. J. Perreault, "Submodule integrated distributed maximum power point tracking for solar photovoltaic applications," IEEE Trans. Power Electron., vol. 28, no. 6, pp. 2957-2967, Jun. 2013.

[6] M. Adly and K. Strunz, "Irradiance-adaptive PV module integrated converter for high efficiency and power quality in standalone and DC microgrid applications," IEEE Trans. Ind. Electron., vol. 65, no. 1, pp. 436-446, Jan. 2018.

[7] S. Sajadian and R. Ahmadi, "Distributed maximum power point tracking using model predictive control for photovoltaic energy harvesting architectures based on cascaded power optimizers," IEEE J. Photovolt., vol. 7, no. 3, pp. 849-857, May 2017.

[8] A. M. S. S. Andrade, L. Schuch, and M. L. da Silva Martins, "High step up PV module integrated converter for PV energy harvest in FREEDM systems," IEEE Trans. Ind. Appl., vol. 53, no. 2, pp. 1138-1148, Mar. 2017.

[9] N. L. Diaz, T. Dragicevic, J. C. Vasquez, and J. M. Guerrero, "Intelligent distributed generation and storage units for DC microgrids - A new concept on cooperative control without communications beyond

droop control," IEEE Trans. Smart Grid, vol. 5, no. 5, pp. 2476-2485, Sep. 2014.

[10] H. Patel and V.Agarwal,"MATLAB-basedmodeling to study the effects of partial shading on PVarray characteristics," IEEE Trans. Energy Convers., vol. 23, no. 1, pp. 302-310, Mar. 2008.

[11] A. Ramyar,H. Iman-Eini, and S. Farhangi, "Global maximum power point tracking method for photovoltaic arrays under partial shading conditions," IEEE Trans. Ind. Electron., vol. 64, no. 4, pp. 2855-2864, Apr. 2017.

[12] C. Olalla, C. Deline, and D. Maksimovic, "Performance of mismatched PV systems with submodule integrated converters," IEEE J. Photovolt., vol. 4, no. 1, pp. 396-404, Jan. 2014.

[13] J. Ahmed and Z. Salam, “An improved method to predict the position of maximum power point during partial shading for PV arrays," IEEE Trans. Ind. Inform., vol. 11, no. 6, pp. 1378-1387, Dec. 2015.

[14] B. N. Alajmi, K. H. Ahmed, S. J. Finney, andB.W.Williams, "A maximum power point tracking technique for partially shaded photovoltaic systems in microgrids," IEEE Trans. Ind. Electron., vol. 60, no. 4, pp. 1596-1606, Apr. 2013. 
[15] H. Patel and V. Agarwal, "Maximum power point tracking scheme for PV systems operating under partially shaded conditions," IEEE Trans. Ind. Electron., vol. 55, no. 4, pp. 1689-1698, Apr. 2008.

[16] T. L. Nguyen and K. S. Low, "A global maximum power point tracking scheme employing DIRECT search algorithm for photovoltaic systems," IEEE Trans. Ind. Electron., vol. 57, no. 10 , pp. $3456-3467$,

Oct. 2010.

[17] Y. Jiang, J. A. Abu Qahouq, and T. A. Haskew, "Adaptive step size with adaptive-perturbation-frequency digital MPPT controller for a single sensor photovoltaic solar system," IEEE Trans. Power Electron., vol. 28, no. 7, pp. 3195-3205, Jul. 2013.

\section{Creative Commons Attribution License 4.0} (Attribution 4.0 International, CC BY 4.0)

This article is published under the terms of the Creative Commons Attribution License 4.0

https://creativecommons.org/licenses/by/4.0/deed.en_US 